\title{
Fabrication of pillared PLGA microvessel scaffold using femtosecond laser ablation
}

This article was published in the following Dove Press journal:

International Journal of Nanomedicine

6 April 2012

Number of times this article has been viewed

\author{
Hsiao-Wei Wang' \\ Chung-Wei Cheng ${ }^{2}$ \\ Ching-Wen $\mathrm{Li}^{3}$ \\ Han-Wei Chang ${ }^{4}$ \\ Ping-Han $\mathrm{Wu}^{2}$ \\ Gou-Jen Wang ${ }^{1,3}$ \\ 'Graduate Institute of Biomedical \\ Engineering, National Chung Hsing \\ University, Taichung, Taiwan, ${ }^{2}$ Laser \\ Application Technology Center, \\ Industrial Technology Research \\ Institute, Tainan County, Taiwan, \\ ${ }^{3}$ Department of Mechanical \\ Engineering, ${ }^{4}$ Department of Chemical \\ Engineering, National Chung Hsing \\ University, Taichung, Taiwan
}

\begin{abstract}
One of the persistent challenges confronting tissue engineering is the lack of intrinsic microvessels for the transportation of nutrients and metabolites. An artificial microvascular system could be a feasible solution to this problem. In this study, the femtosecond laser ablation technique was implemented for the fabrication of pillared microvessel scaffolds of polylactic-co-glycolic acid (PLGA). This novel scaffold facilitates implementation of the conventional cell seeding process. The progress of cell growth can be observed in vitro by optical microscopy. The problems of becoming milky or completely opaque with the conventional PLGA scaffold after cell seeding can be resolved. In this study, PLGA microvessel scaffolds consisting of $47 \mu \mathrm{m} \times 80 \mu \mathrm{m}$ pillared branches were produced. Results of cell culturing of bovine endothelial cells demonstrate that the cells adhere well and grow to surround each branch of the proposed pillared microvessel networks.
\end{abstract}

Keywords: femtosecond laser ablation, pillared microvessel scaffold, polylactic-co-glycolic acid, bovine endothelial cells

\section{Introduction}

The main challenges in tissue engineering are the seeding of specific cells onto the appropriate scaffold, and providing a suitable culturing environment and adequate growth information to modulate the differentiation and proliferation of cells. ${ }^{1,2}$ Cell, scaffold, and growth information are the basic elements of tissue engineering. Scaffolds serve a number of purposes, functioning as the foundation for cell attachment and migration, for the exchange of nutrients, and delivering and retaining of cells and biochemical factors. One of the persistent challenges confronting tissue engineering is the lack of intrinsic microvessels for the transportation of nutrients and metabolites. One feasible solution to this problem is to make an artificial microvascular system to provide regular metabolic distribution.

In general, the structure of a microvascular network is much smaller than that of an artery or a vein. Conventional techniques for the fabrication of artificial blood vessels cannot be adopted as for the fabrication of a microvascular network. Soft lithography using polymers such as polydimethylsiloxane and polylactic-coglycolic acid (PLGA) has been studied and successfully used to make microvessel scaffolds for tissue engineering. ${ }^{3,4}$ Borenstein et al used deep reactive ion etching to make microstructures of a microvessel network on a silicon substrate as a replica mold. They cast microvessel scaffolds of polydimethylsiloxane from replica molds and $\mathrm{O}_{2}$ plasma-assisted bonding. Successful seeding of endothelial cells from human microvessels in polydimethylsiloxane scaffolds was carried out. ${ }^{5-7}$
Correspondence: Gou-Jen Wang Graduate Institute of Biomedical Engineering, National Chung-Hsing University, Taichung 40227, Taiwan

Tel +88 6422840725 extension 320

Fax +88 6422877170

Email gjwang@dragon.nchu.edu.tw 
Wang et al later utilized stainless steel electroforming and silicon electroforming approaches for the manufacture of microvascular scaffolds of polycarbonate and PLGA for bovine endothelial cell seeding. ${ }^{8}$ The microvascular scaffold structure has been optimized for better cell adhesion based on fluid mechanics analysis and computer simulations. ${ }^{9,10}$ In the aforementioned approaches, the microchannels of a scaffold are rectangular in cross-section and usually have dead volumes in the four corners. To solve the dead volume problem, the same group developed microvessel scaffolds with circular microchannels on both polydimethylsiloxane and PLGA substrates using the photoresist melting approach. ${ }^{11,12}$ Borenstein et al have recently reported on the fabrication of another circular cross-sectional microvascular scaffold structure based on the polystyrene substrate. Successful seeding of primary human umbilical vein endothelial cells was observed. ${ }^{13}$ The nanopatterned scaffold has been demonstrated to have greater potential for bovine endothelial cell adhesion and proliferation. ${ }^{14}$ Wang et al further utilized the anodic aluminum oxidization approach for the fabrication of PLGA microvessel scaffolds with nanostructured inner walls. ${ }^{15}$

In conventional microvessel scaffolds, rectangular or circular microchannels form the branches, and it is hoped that the cells can grow along the inner wall of each branch. When a biodegradable material such as PLGA is used, the structure of the scaffold gradually turns opaque and milky over a period of 24 hours. This occurs due to absorption of the cultivation medium and the following hydrolysis, and makes it difficult to use optical microscopy to monitor the progress of cell seeding. ${ }^{12}$ In addition, dynamic seeding can be carried out using a peristalsis pump to give the seeded cells properties similar to those of the endothelial cells of a real capillary. This is the commonly used cell culture method. However, this method has disadvantages, such as aging and cracking of the connection conduit and probable virus infection. Although semidynamic seeding, ${ }^{10}$ which enables periodic exchanges of the cultivation medium 2-3 times a day, can be used to reduce the probability of virus infection, it is not a foolproof solution. If a microvascular scaffold with pillared microvessel networks can be fabricated to replace the reported microchannel-based scaffold, endothelial cells could be seeded around each pillared microvessel branch using the conventional cell-seeding process. This would overcome the disadvantages of the biodegradable microvessel scaffolds. Moreover, pillared microvessel networks can eventually be degraded by the cultivation medium or physiological metabolism. Hence, long-term culture of bovine endothelial cells until complete degradation of the pillared PLGA scaffold can result in an artificial microvessel network that is formed by the bovine endothelial cells surrounding the original pillared PLGA scaffold.

The unique characteristics of ultrashort laser pulses, eg, minimal thermal effects and mechanical damage, from a femtosecond laser can be used to remove or to modify the properties of a material. Femtosecond laser micromachining has been demonstrated to be a versatile tool for precise ablation of microscale and nanoscale features on materials. ${ }^{16-19} \mathrm{~A}$ variety of femtosecond laser microfabricated devices are being used in the photonic, microelectronic, biomedical, and microfluidic fields..$^{20-28}$ They are fabricated from various materials, such as metal, glass, ceramics, polymers, and semiconductors. However, the femtosecond laser micromachining of tissue scaffolding fabricated from biodegradable material is still in the initial stages. Lim et al demonstrated that a femtosecond laser can be used to fabricate arbitrary patterns and pattern arrays on freestanding electrospun polycaprolactone membranes for use as functional tissue scaffolds. ${ }^{29}$ Melissinaki et al reported the production of three-dimensional scaffolds of polylactide-based materials through layer-by-layer multiphoton polymerization. ${ }^{30}$ Ovsianikov et al used the two-photon polymerization
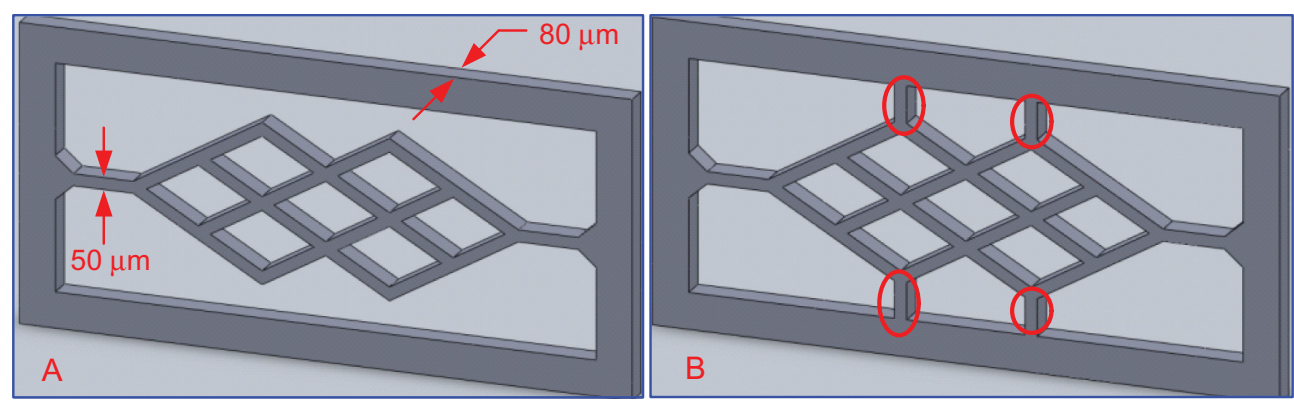

Figure I Microvessel scaffold design. 


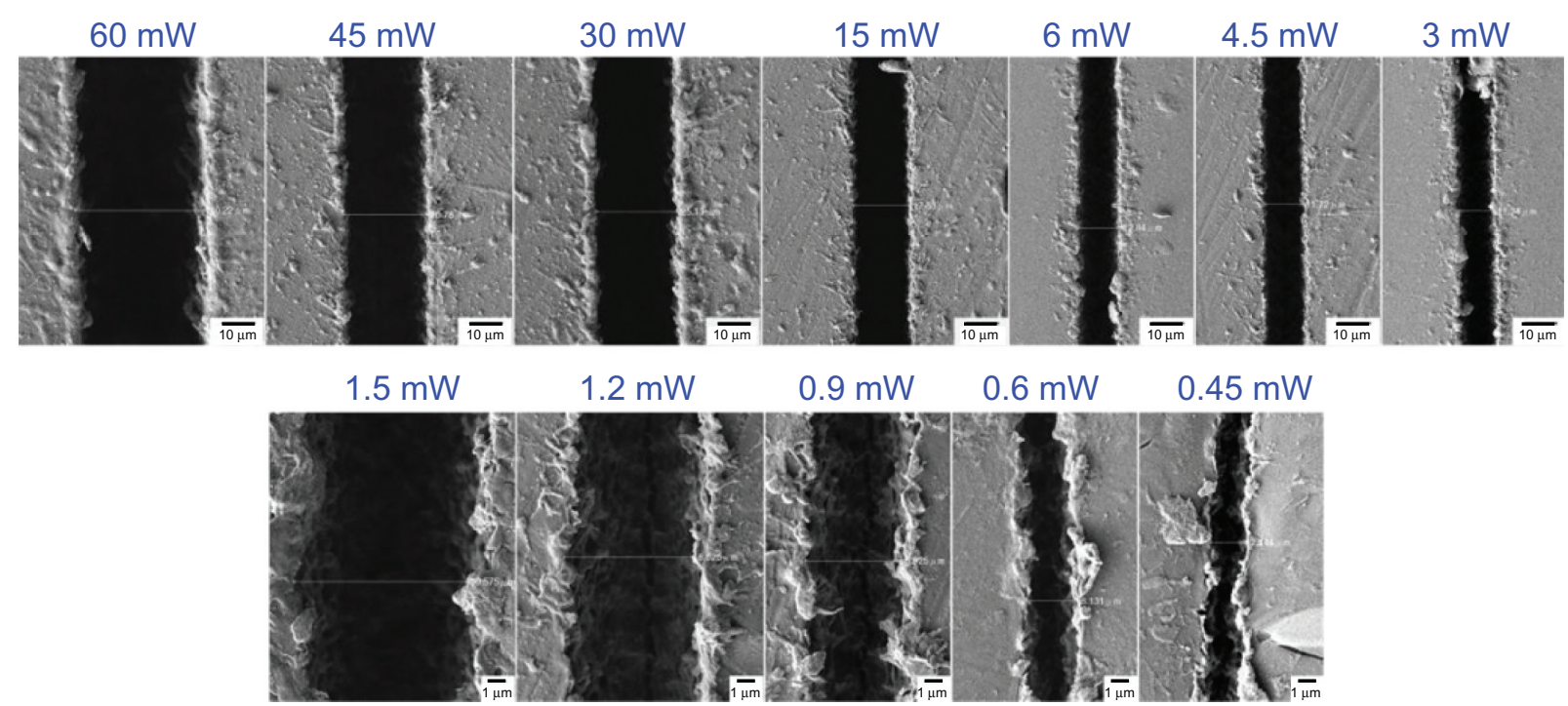

Figure 2 Scanning electron microscopic images of polylactic-co-glycolic acid line patterns fabricated under a constant scanning speed of 0.05 mm/sec and a laser power of $0.45-60 \mathrm{~mW}$.

method to fabricate three-dimensional computer-designed scaffolds on photosensitive methacrylamide-modified gelatin. ${ }^{31}$ However, direct writing of the scaffold structure in a bulk biodegradable material by single femtosecond laser ablation has not yet been reported.

The main purpose of this study was to develop a novel method for the fabrication of artificial microvessel networks which allows a conventional cell seeding process to be implemented and the progress of cell growth to be observed in vitro by optical microscopy. Pillared microvessel scaffolds are fabricated in PLGA using femtosecond laser ablation. Following this process, bovine endothelial cells were cultured on pillared biodegradable microvessel scaffolds using the conventional culturing method. It was expected that the milky or completely opaque appearance of the conventional PLGA scaffold after cell seeding, which occurs due to absorption of the cultivation medium and the cultivation medium contamination, could thus be solved.

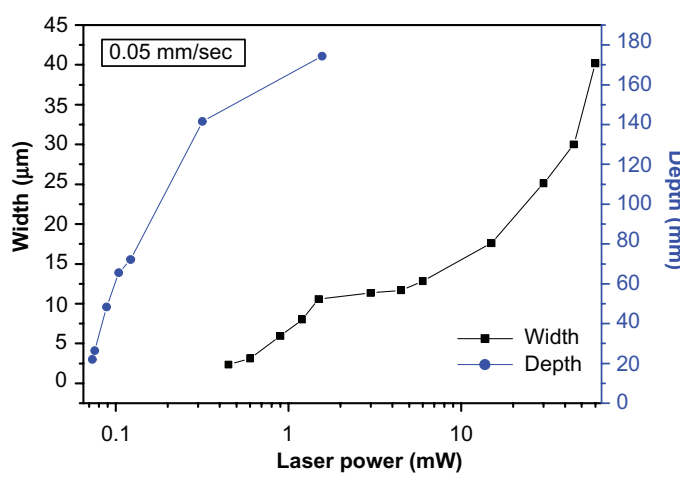

\section{Materials and methods} Femtosecond laser micromachining system for fabricating PLGA scaffolds

A femtosecond laser micromachining system was used for patterning PLGA film. The femtosecond laser used in this study was a regenerative amplified mode-locked Ti:Sapphire laser (Spitfire; Spectra-Physics, Mountain View, CA), with a central wavelength of $800 \mathrm{~nm}$, a repetition rate of $1 \mathrm{kHz}$, a pulse duration of about $120 \mathrm{fsec}$, and a maximum pulse energy of about $3.5 \mathrm{~mJ}$. The polarized Gaussian laser beam was initially attenuated using a rotatable half-wave plate, then incident upon a polarizing beam splitter. The reflected component was routed to a power detector in order to measure the laser energy, while the transmitted component was passed through a mechanical shutter. The laser beam passed through a reflective mirror system, in such a manner that it entered the objective lens (numerical aperture 0.26, M Plan Apo NIR;

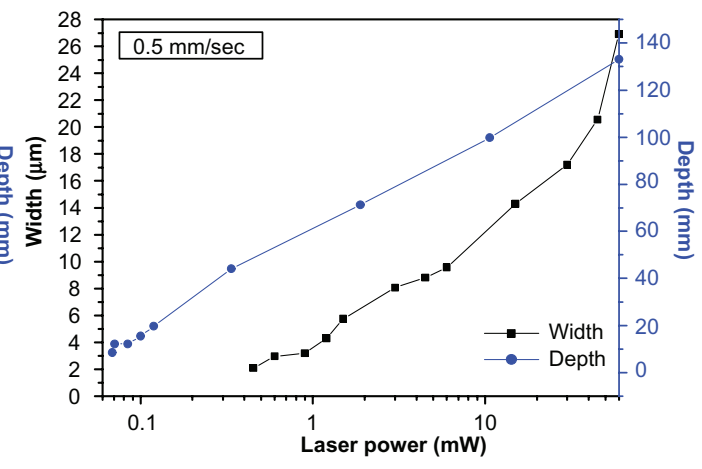

Figure 3 Ablation line width and depth as a function of laser power at scanning speeds of $0.05 \mathrm{~mm} / \mathrm{sec}$ and $0.5 \mathrm{~mm} / \mathrm{sec}$. 

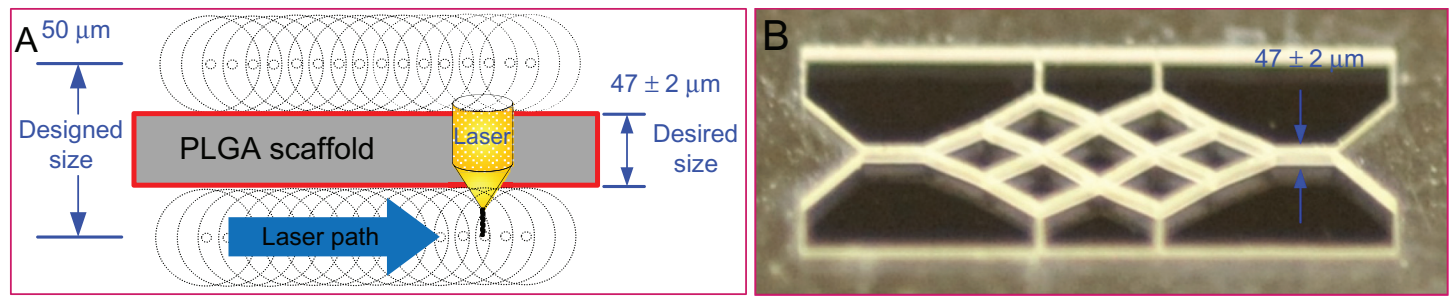

Figure 4 Fabrication strategy for the polylactic-co-glycolic acid scaffold and a scaffold fabricated under laser ablation. (A) Fabrication strategy and (B) fabricated scaffold. Abbreviations: PLGA, polylactic-co-glycolic acid.

Mitutoyo, Singapore) mounted on a $\mathrm{Z}$ stage, and focused normally on the surface of a specimen mounted on an $\mathrm{X}-\mathrm{Y}$ axial micropositioning stage, with a precision greater than $1 \mu \mathrm{m}$. The fabrication process was monitored by a charge-coupled device.

\section{Microvessel scaffold design}

Figure 1 shows two types of scaffolds. The thickness of each branch was $50 \mu \mathrm{m}$. The second type of scaffold, as shown in Figure 1B, has several additional elements (red circled areas) designed to enhance its stiffness, which prevents deflection due to absorption of the culture medium.

\section{PLGA substrate preparation}

PLGA is a copolymer comprised of lactic acid and glycolic acid. The mechanical properties and biodegradability of PLGA are determined by the ratio of lactide to glycolide used for polymerization (eg, PLGA 50:50 denotes a copolymer whose composition is $50 \%$ lactic acid and $50 \%$ glycolic acid). Because a pillared microvessel network with a high mechanical strength is needed to sustain the structure, 85:15 PLGA was adopted in this study.

The PLGA solution was produced by dissolving $85 / 15$ POLY, IV 1.6-1.99 (dL/g), molecular weight 350,000500,000 Da (Sigma-Aldrich, St, Louis, MO) in acetone at a $1: 4 \mathrm{w} / \mathrm{w}$ ratio. The admixture was then stirred by a magnetic agitator at $60^{\circ} \mathrm{C}$ for $30-60$ minutes to ensure complete dissolution. The PLGA solution was then shaken for 15 minutes using an ultrasonic shaker to expel bubbles
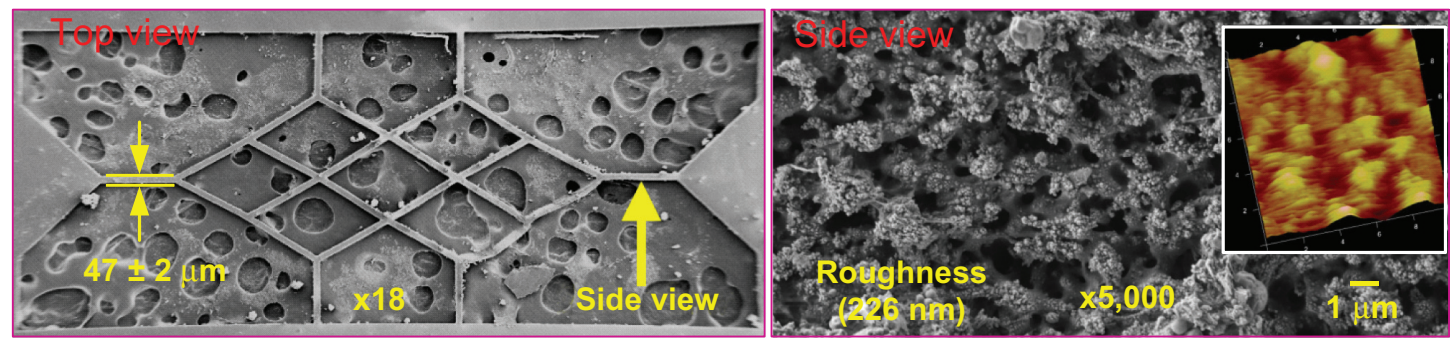

generated during mixing. Finally, the PLGA solution was kept at $4^{\circ} \mathrm{C}$ for polymerization.

\section{Zeta potential measurement}

A DI3100 (Bruker, Karlsruhe, Germany) electric force microscope was used to image the electrostatic surface potential of the laser micromachined surface of the PLGA scaffold.

\section{Surface roughness measurement}

The same device used for electric force microscopy imaging was used in atomic force microscopy mode to measure the surface roughness of the laser micromachined surface on the PLGA scaffold.

\section{Bovine endothelial cells}

In this study, bovine endothelial cells (provided by Professor Chia-Ching Wu, Department of Cell Biology and Anatomy, School of Medicine, National Cheng-Kung University, Taiwan) were used to form the desired capillaries. Bovine endothelial cells $\left(\mathrm{P}_{122}-\mathrm{P}_{125}\right)$ were isolated and cultured in T-75 under standard cell culture conditions (ie, $37^{\circ} \mathrm{C}$, humidity $5 \%, \mathrm{CO}_{2} / 95 \%$ air environment). Bovine endothelial cells were cultured in low glucose Dulbecco's modified Eagle's medium purchased from Gibco BRL (Grand Island, NY), supplemented with 10\% fetal bovine serum and $100 \mathrm{U} / \mathrm{mL}$ penicillin-streptomycin, both purchased from Biological Industries (West Bank, Israel). Each time, $230 \mu \mathrm{L}$ of cell suspension (about 80,000 cells) was coated on the pillared microvessel networks and kept at $37^{\circ} \mathrm{C}$ in $5 \%$ $\mathrm{CO}_{2}$ for the duration of the experiments.

Figure 5 Scanning electron microscopic images of the laser-fabricated scaffold. 

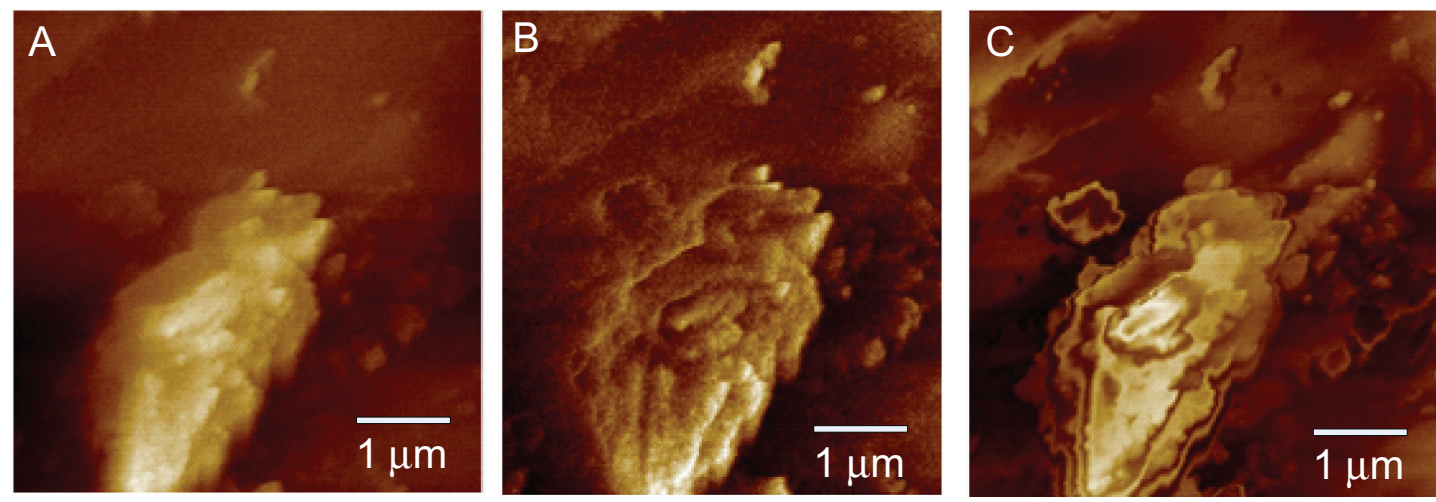

Figure 6 Electric force microscopy images for zeta potential analysis. (A) Electric force microscopy image, (B) phase image, and (C) phase image when the focal length was increased by $3 \mu \mathrm{m}$.

\section{Bovine endothelial cell adhesion and growth}

The adhesion and growth conditions for the bovine endothelial cell cultures on the pillared microvessel networks were examined after staining with phalloidin cell stain (Sigma-Aldrich) for skeleton labeling (588 $\mathrm{nm}$ excitation wavelength) and DAPI nucleic acid stain (Invitrogen, Carlsbad, CA) for nucleus labeling (358 nm excitation wavelength). Briefly, the bovine endothelial cells were washed three times with a phosphatebuffered saline and then incubated at room temperature

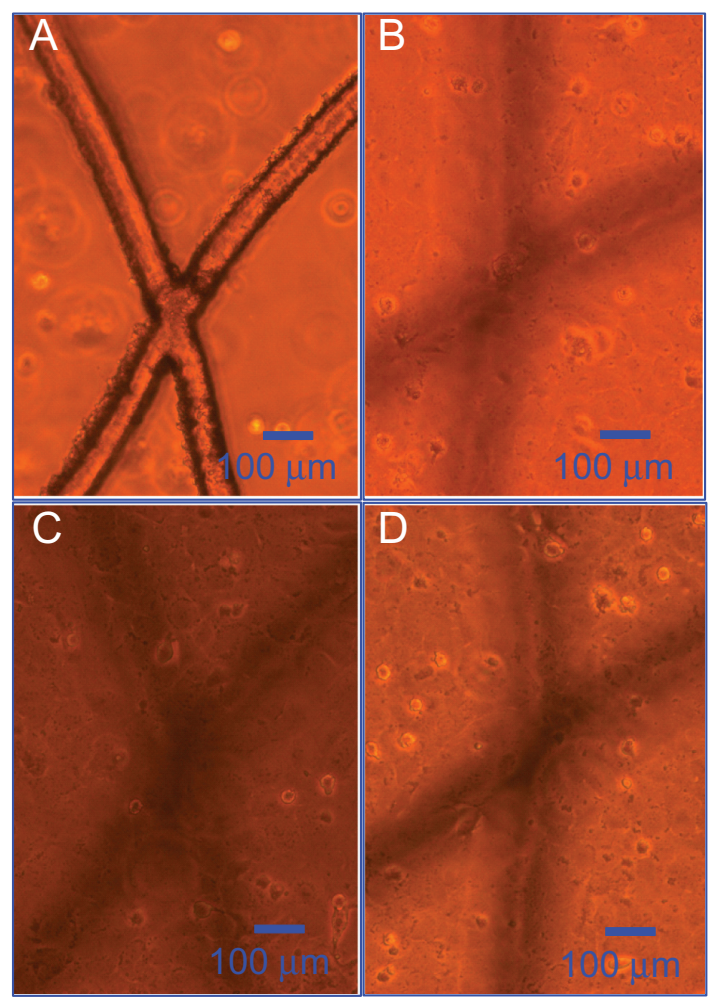

Figure 7 Optical microscopy images of bovine endothelial cell adhesion on the polylactic-co-glycolic acid scaffold. (A) One day's seeding, (B) three days' seeding, (C) five days' seeding, and (D) seven days' seeding. in $4 \%$ paraformaldehyde (Sigma-Aldrich) for 15 minutes to stabilize cells in their original adhesion position. Following the incubation period, cells were soaked in a medium comprised of $0.5 \%(\mathrm{v} / \mathrm{v})$ Triton X-100 (Sigma-Aldrich) in phosphatebuffered saline for 30 minutes and then in $1 \%(\mathrm{w} / \mathrm{v})$ bovine serum albumin supplied by United States Biochemical (Cleveland, OH). The soaking durations for skeleton labeling and nucleus labeling were 30 minutes and 5 minutes, respectively. Both the skeleton and nucleus fluorescent images were taken using an Eclipse 80i inverted microscope (Nikon, Tokyo, Japan) to examine bovine endothelial cell adhesion and growth conditions on the pillared microvessel networks.

\section{Results and discussion PLGA micromachining by femtosecond ablation}

Figure 2 shows scanning electron microscopic images of line patterns fabricated on a PLGA film surface using a constant speed of $0.05 \mathrm{~mm} / \mathrm{sec}$, laser power in the range of $0.45-60 \mathrm{~mW}$, and a single pass. Due to the Gaussian properties of the irradiated laser beam profile, the middle of the scanning area was irradiated by a higher laser energy than the edges. The net peak energy intensity $\left(N E_{p}\right)$ of the focused laser beam was higher than the ablation threshold of the PLGA, and thus the center of the line was ablated, $N E_{p}=N \times E_{p}$, where $N=2 \omega_{0} R / s$ is the number of laser pulses irradiated per focus spot diameter and $E_{p}=E /\left(\pi \omega_{0}^{2}\right)$ is the peak energy intensity. Note that $\omega_{0}$ is the focus spot radius, $R$ is the laser repetition rate, $s$ is the scanning speed, and $E$ is the laser pulse energy. As shown in Figure 2, the width of the line increases with increasing laser power, because the net peak energy per irradiated focus spot diameter is also increased.

The variation of the measured ablation width and depth (obtained from the cross-sectional scanning electron 

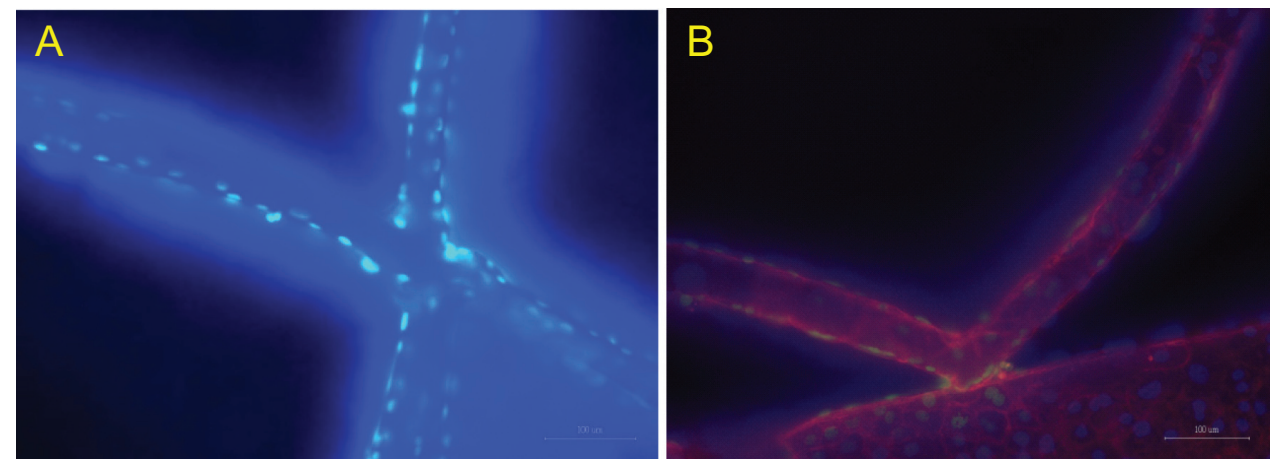

Figure 8 Fluorescent images of cultured cells on the scaffold. (A) DAPI-labeled nuclei and (B) labeled skeletons and nucleus.

microscopic image) as a function of the laser power for scanning speeds of 0.05 and $0.5 \mathrm{~mm} / \mathrm{sec}$ can be seen in Figure 3. It can be observed that a lower scanning speed results in a pattern with greater width and depth. When the irradiated laser power is fixed, a low scanning speed increases the number of laser pulses, ie, $N=2 \omega_{0} R / s$. This results in an increase in the net peak energy intensity per irradiated focus spot diameter. The thermal energy deposited by subsequent pulses must diffuse out through a large area of irradiated material and the width and depth of the pattern grows.

\section{Microvessel scaffold fabrication}

Based on the above analyses of femtosecond laser ablation, the laser focus point is required to move according to the designed geometry, which has dimensions equaling the desired geometry plus the effect size due to laser ablation. Hence, the final dimension of the scaffold after ablation can reach its desired value.
Figure 4 shows the fabrication strategy for the PLGA scaffold and a scaffold fabricated under laser ablation at a constant scanning speed of $0.05 \mathrm{~mm} / \mathrm{sec}$ and a laser power of $60 \mathrm{~mW}$. The width of an individual branch was downsized from the designed $50 \mu \mathrm{m}$ to the desired $47 \mu \mathrm{m}$.

Figure 5 shows the scanning electron microscopic images of the scaffold shown in Figure 4 for further examination of its surface morphology. The holey substrate beneath the scaffold in Figure 5A represents the silver glue used for fixing the scaffold. The thickness of an individual branch was measured to be $47 \mu \mathrm{m}$ (as shown in Figure 5A). Figure 5B shows the nanostructure of the lateral surface of a pillared branch. A surface roughness of $226 \mathrm{~nm}$ was detected. Given that the designed thickness was only $50 \mu \mathrm{m}$, the energy of the laser beam during ablation could be easily absorbed into the PLGA material, allowing the nanostructure surface to be created. However, it has been reported that the nanostructure could enhance the adhesion of bovine endothelial cells on the lateral surface. ${ }^{14}$

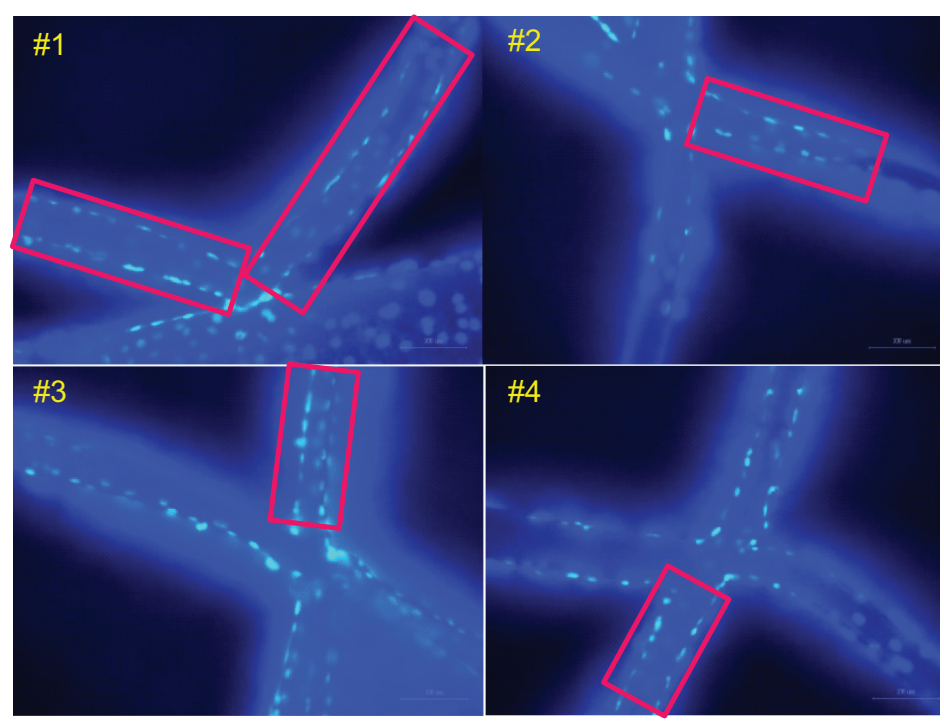

Figure 9 Scaffolds for cell cover ratio estimation. 
Table I Cell cover ratio on the scaffold

\begin{tabular}{llll}
\hline Scaffold & $\begin{array}{l}\text { Scaffold } \\
\text { area }\left(\mu \mathbf{m}^{2}\right)\end{array}$ & $\begin{array}{l}\text { Cell } \\
\text { amount }\end{array}$ & $\begin{array}{l}\text { Cell cover } \\
\text { ratio (\%) }\end{array}$ \\
\hline 1 & 45,585 & 38 & 90.86 \\
2 & 13,583 & 11 & 88.27 \\
3 & 10,191 & 9 & 96.26 \\
4 & 9917 & 8 & 87.93 \\
Average & & & $90.83 \pm 3.85$ \\
\hline
\end{tabular}

An electric force microscopy image of the laser micromachined PLGA surface is shown in Figure 6A. The phase image of Figure 6A is illustrated in Figure 6B. Figure $6 \mathrm{C}$ shows the phase image when the focal length was increased by $3 \mu \mathrm{m}$. There is no sign of an electrical field in Figure $6 \mathrm{C}$. This indicates that there is neither a positive nor negative potential on the PLGA surface. The zeta potential of the free surface exhibited no repulsion to the negativecharged surface of the bovine endothelial cells and enabled better cell adhesion.

\section{Bovine endothelial cell culture}

Figure 7 shows optical microscopy images of the bovine endothelial cell adhesion and proliferation on the PLGA scaffold, as already shown in Figure 3A. It can be observed from Figure 7A that cells had not yet adhered to the pillared microvessel networks after 1 day of seeding. Figure $7 \mathrm{C}$ is the image after
5 days of culturing. It can be seen that cells had adhered well to the scaffold and plate. After 7 days of seeding (Figure 7D), the growth of cells reached saturation conditions.

Figure 8 shows fluorescent images of adhering cells on the PLGA scaffold as shown in Figure 4 at $200 \times$ magnification 10 days after plating. Figure $8 \mathrm{~A}$ is an image of a DAPI-labeled nucleus. The light spots, which denote the locations of the nuclei, indicate that cells definitely adhered to and grew on the pillared scaffold, although the branches of the scaffold were slightly deformed due to absorption of the cultivation medium. Figure $8 \mathrm{~B}$ shows an image combining the phalloidin-labeled skeletons and the DAPI-labeled nucleus excited by different light sources. Firm adhesion of cells could be further confirmed.

The cell cover ratio was estimated based on these four scaffolds, and is shown in Figure 9. The rectangle in each scaffold is selected as the area for counting of cell numbers. The average cell cover ratio was estimated as follows:

$$
\text { Cell cover ratio }=\frac{\text { Cell area } \times \text { Cell amount }}{\text { Scaffold area }} \times 100 \%
$$

where the cell area denotes the average cover area of each cell on the scaffold and was calculated to be $1090 \pm 157 \mu^{2}$. Accordingly, the average cell cover ratio was calculated to be $90.83 \pm 3.85 \%$ (Table 1$)$.
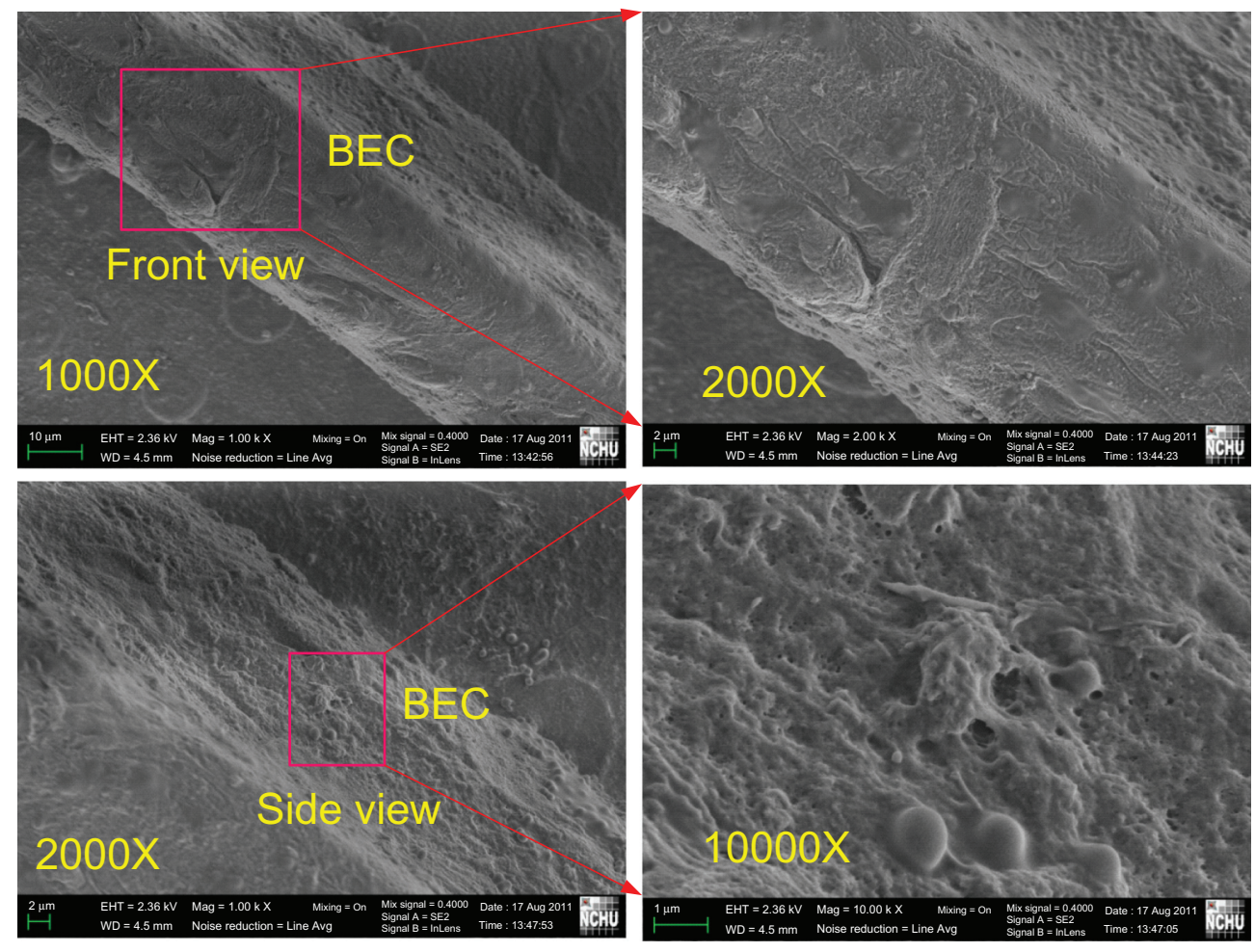

Figure 10 Scanning electron microscopic images of bovine endothelial cells cultured on a branch of a pillared microvessel network for 14 days. 
To confirm further the adhesion and growth of bovine endothelial cells on the proposed pillared microvessel networks, further scanning electron microscopic images were acquired. Figure 10 illustrates the scanning electron microscopic images of bovine endothelial cells cultured on a branch of the pillared microvessel network for 14 days. On the front side, multiple stacks of bovine endothelial cells can be observed in the $2000 \times$ magnification image. Although it was difficult to take a clear side image, bovine endothelial cells were found through a 10,000 magnification image.

These culturing results demonstrate that bovine endothelial cells adhere and grow to surround each branch of the proposed pillared microvessel networks fabricated by femtosecond laser ablation. The milky and completely opaque problems seen in real-time observation of cell growth in conventional PLGA scaffolds after cell seeding can be resolved. Our results are promising, revealing that an artificial microvessel network for tissue engineering can be realized. Because the size of the pillared branch in this study was $47 \mu \mathrm{m}$, the size of capillaries formed by bovine endothelial cells after PLGA degrading is likely to be less than $47 \mu \mathrm{m}$. However, it is still much larger than the smallest capillary (about $3 \mu \mathrm{m}$ ) in the human body. Resolution of the femtosecond laser ablation on soft material such as PLGA requires further improvement.

\section{Conclusion}

A conventional microvessel scaffold usually consists of microvascular networks of microchannels made from biodegradable materials. For those biodegradable microvessel scaffolds, the scaffold structure gradually turns opaque and milky after 24 hours of cell seeding due to absorption of the cultivation medium, followed by hydrolysis. This makes it difficult to monitor the progress of cell seeding using optical microscopy. In this study, the femtosecond laser ablation technique was implemented for fabrication of pillared microvessel scaffolds in PLGA, so the conventional cell seeding process could be implemented and the progress of cell growth could be observed in vitro by optical microscopy. Cell culturing results illustrated by fluorescent images demonstrated that bovine endothelial cells could adhere well and grow, surrounding each branch of the proposed pillared microvessel networks. Because the bovine endothelial cells were not cultured in a microchannel-based scaffold, the milky and completely opaque problems of the conventional PLGA scaffold after cell seeding and cultivation medium contamination problems could be resolved.
In our current work, long-term culture of bovine endothelial cells until complete degradation of the pillared PLGA scaffold is in progress. An artificial microvessel network formed by bovine endothelial cells surrounding the original pillared PLGA scaffold is expected to be obtained. It is hoped that the endothelialized networks produced by the proposed method in this study can be further applied to therapeutic devices, such as engineered tissue constructs and organ assistance systems.

\section{Acknowledgments}

The authors thank the Industrial Technology Research Institute of Taiwan for their financial support of this research. The support of the National Science Council of Taiwan under grant number NSC100-2221-E-005-014-MY3 is also highly appreciated.

\section{Disclosure}

The authors report no conflicts of interest in this work.

\section{References}

1. Lanza R, Langer R, Vacanti J. Principles of Tissue Engineering. 2nd ed. San Diego, CA: Academic Press; 2007.

2. Wang W, Soper SA. Bio-MEMS Technologies and Applications. Boca Raton, FL: Taylor and Francis CRC; 2007.

3. Xia Y, Whitesides GM. Soft lithography. Annu Rev Mater Sci. 1998;29: 153-184.

4. Rogers JA, Nuzzo RG. Recent progress in soft lithography. Mater Today (Kidlington). 2005;8:50-56.

5. Borenstein JT, Terai H, King KR, Kaazempur-Mofrad MR, Vacanti JP. Microfabrication technology for vascularized tissue engineering. Biomed Microdevices. 2002;4:167-175.

6. Shin M, Matsuda K, Ishii O, et al. Endothelialized networks with a vascular geometry in microfabricated poly(dimethyl siloxane). Biomed Microdevices. 2004;6:269-278.

7. Fidkowski C, Kaazempur-Mofrad MR, Borenstein, JT, et al. Endothelialized microvasculature based on a biodegradable elastomer. Tissue Eng. 2005;11:302-309.

8. Wang GJ, Chen CL, Hsu SH, Chiang YL. Bio-MEMS fabricated artificial vascular network for tissue engineering. Microsystem Technologies. 2005;11:120-127.

9. Wang GJ, Hsu YF. Structure optimization of microvascular scaffolds. Biomed Microdevices. 2006;8:51-58.

10. Wang GJ, Hsu YF, Hsu SH, Horng RH. JSR photolithography based microvascular fabrication and cell seeding. Biomed Microdevices. 2006;8:17-28.

11. Wang GJ, Ho KH, Hsu SH, Wang KP. Microvessel scaffold with circular microchannels by photoresist melting. Biomed Microdevices. 2007;9: 657-663.

12. Wang GJ, Hsueh CC, Hsu SH, Hung HS. Fabrication of PLGA microvessel scaffolds with circular microchannels using soft lithography. J Micromech Microeng. 2007;17:2000-2005.

13. Borenstein JT, Tupper MM, Mack PJ, et al. Functional endothelialized microvascular networks with circular cross-sections in a tissue culture substrate. Biomed Microdevices. 2010;12:71-79.

14. Wang GJ, Lin YC, Li CW, Hsueh CC, Hsu SH, Hung HS. Fabrication of orderly nanostructured PLGA scaffolds using anodic aluminum oxide templates. Biomed Microdevices. 2009;11:843-850. 
15. Wang GJ, Lin YC, Hsu SH. The fabrication of PLGA microvessel scaffolds with nano-patterned inner walls. Biomed Microdevices. 2010;12: 841-848.

16. Malek CK, Robert L, Salut R. Femtosecond laser machining and lamination for large-area flexible organic microfluidic chips. Eur Phys J Appl Phys. 2009;46:12503.

17. Kruger J, Kautek W. The femtosecond pulse laser: a new tool for micromachining. Laser Phys. 1999;930-940.

18. Chimmalgi A, Choi TY, Grigoropoulos CP, Komvopoulos K. Femtosecond laser apertureless near-field nanomachining of metals assisted by scanning probe microscopy. Appl Phys Lett. 2003;82:1146-1148.

19. Cheng CW, Shen WC, Lin CY, Lee YJ, Chen JS. Fabrication of micro/ nano crystalline ITO structures by femtosecond laser pulses. Appl Phys A. 2010;101:243-248.

20. Kamata M, Obara M, Gattass RR, Cerami LR, Mazur E. Optical vibration sensor fabricated by femtosecond laser micromachining. Appl Phys Lett. 2005;87:051106.

21. Maselli V, Osellame R, Cerullo G, et al. Fabrication of long microchannels with circular cross section using astigmatically shaped femtosecond laser pulses and chemical etching. Appl Phys Lett. 2006;88:191107.

22. Chung SH, Clark DA, Gabel CV, Mazur E, Samuel AD. The role of the AFD neuron in C.elegans thermotaxis analyzed using femtosecond laser ablation. BMC Neurosci. 2006;7:30.

23. Gaspard S, Forster M, Huber C, et al. Femtosecond laser processing of biopolymers at high repetition rate. Phys Chem Chem Phys. 2008;10: 6174-6181.
24. An R, Uram JD, Yusko EC, Ke K, Mayer M, Hunt AJ. Ultrafast laser fabrication of submicrometer pores in borosilicate glass. Opt Lett. 2008;33:1153-1155.

25. Vorobyev AY, Makin VS, Guo C. Brighter light sources from black metal: significant increase in emission efficiency of incandescent light sources. Phys Rev Lett. 2009;102:234301.

26. Lee CY, Chang TC, Wang SC, Chien CW, Cheng CW. Using femtosecond laser to fabricate highly precise interior three dimensional microstructures in polymeric flow chip. Biomicrofluidics. 2010;4:46502.

27. Chen CH, Chao TC, Li WY, et al. Novel U-shape gold nanoparticlesmodified optical fiber for localized plasmon resonance sensing. Microsystem Technologies. 2010;16:1207-1214.

28. Cheng CW, Lee YJ, Shen WC, Chen JS, Chien CW. Femtosecond laserinduced crystallization of amorphous indium tin oxide film on glass substrate for patterning applications. J Laser Micro Nanoengineering. 2009;4:165-169.

29. Lim YC, Johnson J, Fei Z, et al. Micropatterning and characterization of electrospun poly( $e$-caprolactone)/gelatin nanofiber tissue scaffolds by femtosecond laser ablation for tissue engineering applications. Biotechnol Bioeng. 2011;108:116-126.

30. Melissinaki V, Gill AA, Ortega I, et al. Direct laser writing of 3D scaffolds for neural tissue engineering applications. Biofabrication. 2011;3: 045005 .

31. Ovsianikov A, Deiwick A, Van Vlierberghe S, et al. Laser fabrication of three-dimensional CAD scaffolds from photosensitive gelatin for applications in tissue engineering. Biomacromolecules. 2011;12:851-858.
International Journal of Nanomedicine

\section{Publish your work in this journal}

The International Journal of Nanomedicine is an international, peerreviewed journal focusing on the application of nanotechnology in diagnostics, therapeutics, and drug delivery systems throughout the biomedical field. This journal is indexed on PubMed Central, MedLine, CAS, SciSearch $\AA$, Current Contents ${ }^{\circledR} /$ Clinical Medicine,

\section{Dovepress}

Journal Citation Reports/Science Edition, EMBase, Scopus and the Elsevier Bibliographic databases. The manuscript management system is completely online and includes a very quick and fair peer-review system, which is all easy to use. Visit http://www.dovepress.com/ testimonials.php to read real quotes from published authors. 